\title{
Preface to the Special Section on the 10th Information Systems Foundations Workshop
}

\section{Sigi Goode}

Associate Professor (Information Systems)

Australian National University

sigi.goode@anu.edu.au

It's difficult to believe that it's been 20 years since the first Information Systems Foundations Workshop. The workshop series was begun by Kit Dampney in 1999 at Macquarie University. Thereafter, the workshop has been held biennially at the Australian National University. A number of people have come and gone in that time. However, it's heartening to note that the workshops have maintained their collaborative, collegiate and thoughtful approach to new work, new ideas and new scholars.

In this, the 10th workshop, the focus was on the theoretical foundations of information systems at the social intersection. In particular, papers had to clearly address some theoretical body or bodies of knowledge in the information systems or a related domain, and the implications for practice of the theory or theories under consideration. We sought papers that are carefully argued, stimulating, speculative and controversial.

We received papers on a variety of topics, from which a number were selected for presentation at the workshop. From these papers, three feature in this special section. In "Explanations as Discourse: Towards Ethical Big Data Analytics Services", Sadaf Afrashteh, Ida Someh and Michael Davern use the lens of discourse ethics to examine the use of explanations arising from big data analytics. In "The Challenges Involved in Establishing a Research Technique", Roger Clarke identifies conceptual and methodological challenges and processes involved in the development of new research techniques. In "Making IS Relevant in a Connected World: Revisiting the Intellectual Structures Framework", Henry Linger and Helen Hasan revisit the Intellectual Structures Framework against the backdrop of an ad-hoc, diverse IS field. Each of these works witnessed lively discussion at the workshop.

The papers presented in this special section were accepted following a double-blind peerreview process. The workshop relies each year on the time and effort of a number of anonymous reviewers - it is these anonymous reviewers who truly embody the vital spirit of the workshop. I am also grateful to the other program chairs, Prof. John Campbell and Prof. Kai Riemer for their support, and to Prof. Shirley Gregor for delivering the keynote address.

Finally, as many know, we lost our dear friend and colleague, Prof. John Campbell, not long after the ISF workshop. John was a guiding light and a longstanding contributor to the ISF workshop series over many years. We miss John terribly.

Copyright: (c) 2020 Goode. This is an open-access article distributed under the terms of the Creative Commons Attribution-NonCommercial 3.0 Australia License, which permits noncommercial use, distribution, and reproduction in any medium, provided the original author and AJIS are credited. 


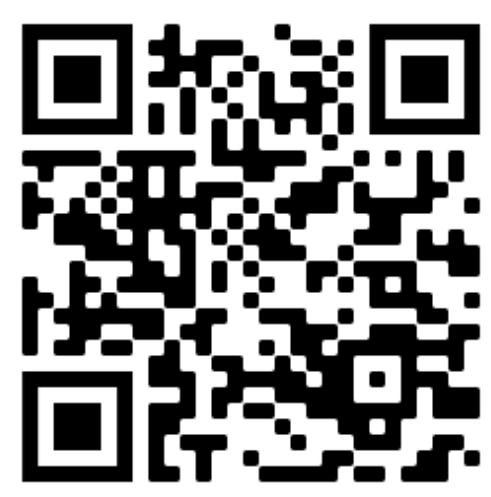

